\title{
When Is a Family a Family? Evidence from Survey Data and Implications for Family Policy
}

\author{
Martha S. Hill \\ Institute for Social Research, University of Michigan
}

\begin{abstract}
This article examines the correspondence between common assumptions about the American family and actual patterns. The assessment is based on national data on individuals, households, and families. Findings indicate that the coresident nuclear model should be considered $a$ model rather than the model of family. Past as well as current marital ties need to be considered in defining "family," and divorce rather than death should be the expected cause of losing the main breadwinner in the family, except among elderly women. Parent-child ties to either young or adult children often span separate households. Coresidents can include individuals other than nuclear family members, and change rather than stability is the modal pattern in living arrangements. Rather than shaping concepts of the family from a single mold, policy makers and researchers are better advised to recognize the diversity and fluidity in family and household structures.
\end{abstract}

KEY WORDS: children, family, household, policy.

\section{Introduction}

The family is a basic unit of social and economic organization and thus forms the foundation for wide-ranging policies, from income taxes to child and dependent care, child support, welfare, social security, family leave, and family planning. Underlying all of these poli-

Martha S. Hill is Associate Research Scientist at the Survey Research Center, Institute for Social Research, University of Michigan, Ann Arbor, MI 48106-1248. Her major research interests include economics of the family, intergenerational transmission, intergenerational transfers, labor economics, and poverty and welfare. She received her Ph.D. in Economics from the University of Michigan in 1977.

The author wishes to thank Wei-Jun Jean Yeung for her assistance in merging the large PSID files in the difficult climate of changing computer resources. Thanks also to Phyllis Moen for very helpful comments and to the editor and anonymous reviewer for their suggestions and patience. 
cies are assumptions about what constitutes a family and what types of families should be eligible for what benefits (see Brandon, 19931994; DaVanzo \& Rahman, 1993; Ellwood, 1993; Levitan \& Gallo, 1990 , for discussions of the ties between family structure and specific policies).

Family structure, relational ties, living arrangements, and the pooling and distribution of resources are all important dimensions of families as viewed from both policy and research perspectives. Information about these aspects, however, is often incomplete. In many situations it is unclear what relatives a person actually has (as in the case of children living apart from parents or multigenerations living together), how many distinct economic units reside under the same roof (as in the case of elderly parents living with their children or young adult children returning to their parents' home), or how many economic units mingle across households (as with adult children transferring money to elderly parents residing elsewhere). Rarely is there any sense of the degree of permanency of the family structure or of living arrangements. With such limitations, it is possible that the policy and research assumptions about the American family may be far afield from the reality the public faces and that the inconsistencies produce ill-fitting policies.

This article attempts to draw together existing national data in an exploration of the correspondence between policy makers' and researchers' assumptions about the American family and actual population patterns. The focus is on the coresident nuclear family and departures from that model.

\section{Defining "Family"}

In considering what defines a family, it can be important to make distinctions about binding ties of blood, adoption, and marriage as well as who lives with whom. For researchers and policy makers alike, other vital distinctions include who pools income with whom for major items of expense and how resources are distributed across family members. It is important to keep in mind the basic functions of a family, which include providing for the basic needs of its members (e.g., goods, services, socio-emotional satisfaction) and children's socialization (Koo \& Gogan, 1990). Family members contribute resources, consume goods and services, help raise children, and build and share socio-emotional bonds. They play an interactive role in both supply and demand for human needs, and changes in family 
structure can substantially shift the balance in supply and demand and the well-being of family members.

The model family for policy design has been a coresident nuclear unit with the husband/father as the main breadwinner and death as a prominent reason for losing the main breadwinner. The characterization of family that underlies a great deal of current U.S. familyrelated policies developed in the 1930 s, when the model for a family was a coresident nuclear family composed of an adult male, who was the main breadwinner, his wife, who was a full-time parent and did not participate in the labor market, and young children. (See Burkhauser \& Duncan, 1989; Glazer, 1988; Hernandez, 1993; Levitan, Belous, \& Gallo, 1988; Wetzel, 1990.)

The general premise underscoring social support policies has been that public policies should buffer families from economic hardship by protecting the main breadwinner from serious labor market difficulties (e.g., unemployment, low wages, retirement with inadequate pension funds) or ensuring an income flow to young children or elderly women who had lost their main breadwinner to death (a prime cause of the loss of the main breadwinner when the social support legislation of the $1930 \mathrm{~s}$ was crafted). ${ }^{1}$ Norms in the $1930 \mathrm{~s}$ were that women, and especially mothers, did not participate in the labor market; hence, encouragement of labor force participation of mothers with no breadwinning husband was not a policy directive.

With the exception of changing expectations about the role of women in the labor market, these premises have continued to form the foundation for a great deal of public policy. For wives and mothers the mores have shifted from encouragement of the roles of homemaker and full-time parent to encouragement of employment once the youngest child reached school age (a 1960s vision) and, more recently, encouragement of training and employment even when the children are very young. (See Blum, 1994, for a description of the changing visions of mothers in the historical development of major national programs to assist families with children.)

Thus

1. in terms of family structure, the key assumption has been that a family is a nuclear family, consisting of a husband, wife, and (young) children (how adult children fit into the picture is less clear); and

2. in terms of economic behavior, the husband is expected to be part of the labor force, whereas expectations about the labor force role of the wife (and mother) have fluctuated over time; the norm 
for wives and mothers has changed from viewing them as nonparticipants, to participants only after children reach school age, to participants regardless of the presence of young children in the home.

Other premises underlying policy making and research on family-related issues include the following:

3. in terms of relational ties, blood, adoption, and marital ties are important in defining who is a family member and who is not;

4. in terms of living arrangements, coresidence is important in defining family members; and

5. in terms of resource distribution, family members, particularly those coresiding and possibly those living apart, pool and share resources.

This article explores the fit between these normative assumptions and actual population tendencies using data uniquely suited to investigation of relational ties, family structure, and living arrangements. The emphasis is on these three dimensions of family.

The economic behavior and resource distribution dimensions of family are also important but are only touched upon here. Limited data on time use other than labor force participation and limited data on the pooling, use, and distribution of resources, especially within households, hinder exploration of the fit between assumptions and tendencies in the realms of economic behavior and resource distribution. Without better data on time use, there is no clear picture of the changes in patterns of housework and of parental care of children stemming from the changing role of women in the labor market.

The available data concerning the distribution of resources point to important functions of the family. In the United States, direct transfers of services, goods, and money between coresiding family members are at least as large as all government transfer programs combined (Morgan, 1983, 1984). Transfers between individuals living apart are smaller in the aggregate but have been measured more often in recent years than has the intrahousehold distribution of resources. A sizable portion of adults engage in interhousehold transfers of either time or money, and the amount of the transfers is not trivial, especially if it is considered support (as opposed to a gift or a loan). ${ }^{2}$ Transfers between parents and children dominate private transfers (Cox \& Raines, 1985; MacDonald, 1990; Schoeni, 1993), and the flow 
of interhousehold help tends to run from parents to children more than the reverse (Eggebeen, 1992; Hill, Morgan, \& Herzog, 1993; MacDonald, 1990; Morgan, Schuster, \& Butler, 1991; Schoeni, 1993; Spitze \& Logan, 1992). The interhousehold transfers involve adult children as well as young children. ${ }^{3}$ Hence the function of the family to distribute resources among its members extends across as well as within dwelling units and persists even after children become adults. The picture of the role of family in the distribution of resources is far from complete, however, without better information about the pooling and distribution of resources by family members living together.

\section{Data for Comparing Family vs. Household Structure}

\section{Shortfalls in Survey Data on Family Structure}

Conventional approaches to the collection and processing of demographic data relating individuals by blood, marriage, adoption, or coresidence can hinder comprehensive identification of relational ties. Most surveys are household-based studies, using definitions of family that derive more from living arrangements than kinship ties. The data on family relationships are most typically gathered by asking the relationship of each individual in a household to the "household head" (or "householder"). This approach can produce an incomplete accounting of relationships between all relevant pairs of individuals in the household, especially in multigenerational households, and miss key family members living elsewhere.

The problem with respect to coresident family members stems from the fact that knowing only the relationship of two individuals $\mathrm{A}$ and $\mathrm{B}$ to a third individual $\mathrm{C}$ (i.e., the household head or householder) does not always reveal the relationship between $\mathrm{A}$ and $\mathrm{B}$. Take, for example, relationship-to-head data that indicate that $\mathrm{A}$ is the daughter and $\mathrm{B}$ is the granddaughter of C. Based on this information alone, it is unclear whether $A$ is the mother or aunt of $B$, yet this can be a very important distinction for policy makers and researchers interested in issues relating to young mothers, some of whom coreside with sisters in their parents' home.

What is needed is information on the relationships between pairs of individuals other than the household head, and, indeed, direct questions about the relationship between all pairs of individuals are occasionally included in surveys. The Survey of Income and Program Participation (SIPP) takes this approach in the household relationships topical module that is administered once per panel. To save on interviewing time and burden, an alternative approach (used each wave in SIPP and in the 1983-1984 waves of PSID) is more frequently used. This alternative involves identifying the parents and spouse of each individual in the household if those relatives are part of the household. This reveals the full complement of family units within a household but does not necessarily clarify all pairwise relational ties. 
Knowing the full complement of family units within a household or even the relationships between all pairs of coresiding individuals, though, is not sufficient for some issues. Relationships between persons living apart are central to issues such as support of children by noncustodial parents or support of frail parents in nursing homes. Because of high rates of divorce and a large proportion of births occurring out of wedlock, many young children live apart from at least one parent. Once they reach adulthood, most children live apart from their parents, thus family ties involving adult children tend to span multiple households. The structure of and linkages connecting nonresident family members have received considerably less attention than coresident family structures, despite the potential for strong economic ties based on relational rather than coresidency ties.

Identifying key nonresident as well as coresident ties requires additional relational information. Comprehensive data on marital, fertility, and adoption histories (as collected in the PSID since 1985, SIPP, and other surveys) aid in the identification of key relatives whether they live together or apart. But marital, fertility, and adoption histories collected only from coresident family members may omit important information when key family members are absent from the household. Marital and fertility histories gathered from all eligible coresidents will not identify both parents of a child, for example, if the child was born out of wedlock and one parent is absent from the child's household. Fertility histories of relatives absent from the household may be needed to determine the full parentage of children. This information is rarely collected in surveys.

\section{Primary Data Source}

A number of surveys collect data needed to study relational and coresidency ties. The current analysis relies primarily on the Panel Study of Income Dynamies (PSID) because it contains a broad range of relational and coresidency information tracked over a long period of time. For some topics, though, other data sets, such as the Survey of Income and Program Participation (SIPP), the Current Population Survey (CPS), and Vital Statistics of the United States form the basis of the current analysis.

The PSID has been following a sizable sample of the American population and its progeny for over two decades, conducting annual interviews on economic status, family composition, and a wide range of other topics of interest to social scientists. Family structure was not anticipated to be of major importance at the study's start, so the PSID is typical of most household-based studies in having as its central core of relational data the relationships between coresidents and the family (or household) head. ${ }^{4}$ In the mid-1980s, however, the PSID began supplementing its relationship-to-head data with comprehensive birth, marriage, and adoption histories. These enhancements facilitated the creation of a special file, known as the PSID Relationship File, which is especially well suited to comparisons of relational and coresidency ties.

The PSID Relationship File provides two sets of relationships: (a) an 18year (1968-1985) span of annual indicators of relationship to head of all indi- 
viduals who were members of a family unit and (b) comprehensive marital, fertility, and adoption histories gathered in the eighteenth year of the observation span (1985) and, hence, after some attrition had occurred. The 18-year observation period provides a wide span of years for relationships to develop and change, and the Relationship File provides information on the full multiyear character of those relationships. Ambiguities in relationships, especially prominent in the early years of the PSID, were clarified using the subsequent data collected in the retrospective demographic histories gathered at the end of the observation period along with all 18 waves of PSID data concerning relationship to head.

The Relationship File uses all this information to relate, on a pairwise basis, individuals who were ever part of, or have derived from, the same original household. The relationship variables have been computer-derived by first devising a set of basic building blocks, or "primitives," that are the components from which complex relationships can be built and then designing a computer algorithm with which to build the relationships. ${ }^{5}$ See the Appendix for more detail about this process.

The Relationship File is used to identify people related in a particular way, and information from the PSID's 1968-1985 main file is merged with it to produce estimates for the population. ${ }^{6}$ The sample consists of PSID sample members residing in interviewed family units in 1985 . The data are weighted by the 1985 weight to represent the 1985 U.S. population. ${ }^{7}$

\section{The Fit between Assumptions and Current Conditions}

The central question of this article is, How well do the assumptions about family that underlie policy design fit with present circumstances? To address this issue, the article first examines the fit of recent empirical patterns to the model American family-a coresident nuclear family. Next is an exploration of specific aspects of family structure, relational ties, and living arrangements bearing on the fit. In this investigation, empirical estimates are disaggregated by age and sex because underlying basic demographic rates that shape family structure and living arrangements (e.g., rates of childbirth, marriage, divorce, remarriage, and death) differ by these factors. Ideally, the estimates would also be disaggregated by race, but sample size limitations for some age/sex subgroups often preclude doing so.

\section{The Model Family}

Assessments of the fit of actual American families to the model of a coresident nuclear family should take account of life-course variation in an individual's set of nuclear families. Life begins as a child in one nuclear family (the family of birth) and then shifts to a different nu- 
clear family (the procreative family) in adulthood when marriage and procreation occur. Hence the relatives who are key to a nuclear family tend to vary with age. For young individuals the family of birth is most relevant, and the presence of both of the individual's parents in the household is a requisite of a coresident nuclear family. For adults their procreative family is most relevant, and the presence of all children and a spouse is key in designating the family as a nuclear family living together under one roof.

How prevalent are nuclear families? Figures under the heading "Household Structure" in Table 1 indicate that, even taking account of both forms of nuclear family, the model of a coresident nuclear family does not fit most age groups of adults. The coresident nuclear family, identified for young children by the presence of both parents (see the right-most column of Table 1), is the modal family situation of U.S. children (individuals under age 20) but does not characterize the family situation of about one-quarter of them. It is a poor characterization of the family situation of adults, for whom the key identifying characteristic is presence of a spouse and all children. Adults are rarely in a coresident nuclear family of birth, and only among those aged $30-39$ is the norm to be in a procreative nuclear family living together under one roof (fourth column of figures under the heading "Household Structure"). Adults aged 50 or older are rarely in a coresident nuclear family with the full complement of members.

These data suggest that the coresident nuclear family should be considered a model, but not the only one, for policy design. This is especially applicable to policies pertaining to older adults, but it applies to most age groups of adults and to children as well.

For elderly persons, an important living arrangement to take into account is living alone. Substantial proportions of the elderly live alone. In fact, the elderly (aged 75 or older) residing in households are as likely to live alone as they are to live with other persons (Rawlings, 1993, Table 17).

For children's issues several recent trends need to be taken into account. Sharply rising divorce rates plus large increases in the percentage of births to unmarried mothers since the 1960s combine to make the single-parent household a prominent living arrangement for children (Bianchi, 1990). SIPP data (Furukawa, 1994, Tables 2-3) indicate, for example, that as of summer 1991, 96.7\% of children under age 18 were living with at least one parent, but only $72.8 \%$ were living with two parents. Remarriage often follows divorce, so even the two-parent living arrangements contain variation in the relationship 


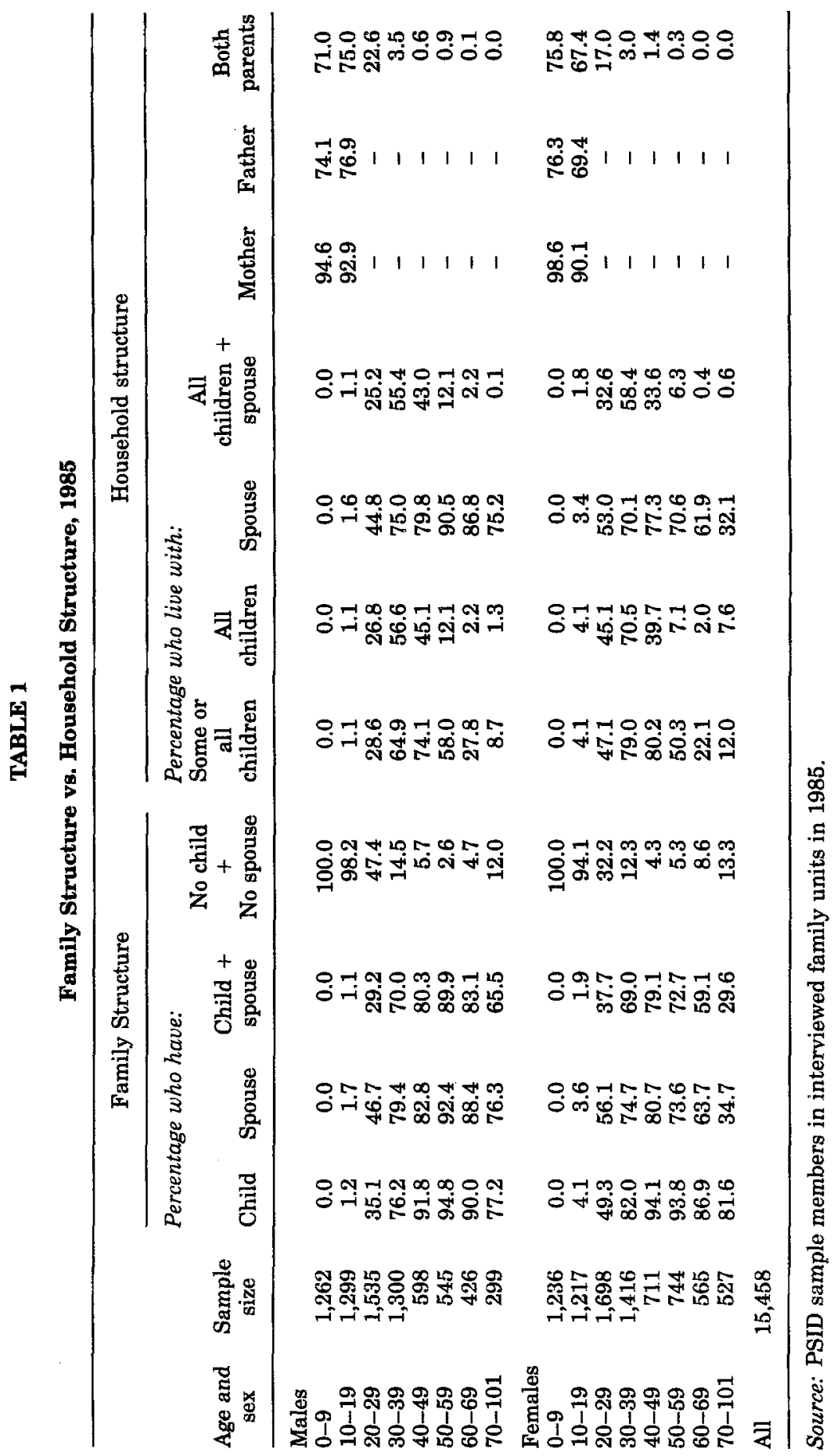


of the child to the parents: only $84.8 \%$ of the children in two-parent homes were living with both biological parents, whereas $9.4 \%$ were living with a stepparent. About one-quarter of the women who give birth annually are unmarried so many children are growing up without a father present in their household (Bachu, 1993, Table B). A nontrivial portion of children (12.5\% in summer 1991) are also growing up spending at least some time in an extended household, many with grandparents and many with aunts and uncles (Furukawa, 1994, Tables $7 \& 10$ ).

\section{Loss of Main Breadwinner}

A variety of policies attempt to prevent or ameliorate economic hardship resulting from the loss of the main breadwinner, but how best to accomplish that depends on the cause of the loss and the availability of other family members to step in to substitute as the main breadwinner. The premise underlying many public policies, such as welfare and social security, is that mortality is the primary cause of the loss of the main breadwinner. This assumption has fostered policies directing the transfer of public funds to the deceased's dependent survivors. If the main breadwinner is lost because of some other event, such as divorce or failure to acknowledge parenting a child, the policy alternatives shift in the direction of enforced transfer of private funds from an absent but still living "main breadwinner" to dependent members of his (or her) procreative nuclear family. Because in married-couple nuclear families the husband is typically characterized as the main breadwinner, the pronoun "he" is often used in conjunction with the term "main breadwinner" and mothers and children are typically characterized as the dependents.

As Table 2 illustrates, the premise that mortality is the prime cause of the loss of the main breadwinner is currently applicable only among the higher ages, most especially among elderly women. Divorce is a much more frequent cause of the loss of a spouse at most ages, and remarriage among the divorced is common. From their teens through their forties women are far more likely to have lost a spouse to divorce than to death, and even in their fifties women are more likely to have experienced divorce then widowhood (compare the first and second column of figures in Table 2). The loss of a spouse to death is now an event experienced primarily by elderly women. About one-quarter of the women in their sixties and half of the women aged 70 or older have a deceased spouse. Men are much less likely to lose a 


\section{TABLE 2}

Percentage Who Have Lost or Gained a Spouse, by Cause of Loss, 1985

\begin{tabular}{lccc}
\hline $\begin{array}{c}\text { Age and } \\
\text { sex }\end{array}$ & $\begin{array}{c}\text { Percentage who have: } \\
\text { Lost a spouse } \\
\text { to death }\end{array}$ & Divorced & $\begin{array}{c}\text { Divorced but have } \\
\text { remarried }\end{array}$ \\
\hline Males & & & \\
$0-9$ & 0.0 & 0.0 & 0.0 \\
$10-19$ & 0.0 & 0.0 & 0.0 \\
$20-29$ & 0.1 & 6.0 & 3.4 \\
$30-39$ & 0.5 & 22.9 & 15.8 \\
$40-49$ & 0.8 & 34.5 & 22.3 \\
$50-59$ & 2.5 & 21.7 & 18.0 \\
$60-69$ & 11.6 & 18.1 & 15.3 \\
$70-101$ & 19.2 & 16.5 & 11.0 \\
Females & & & \\
$0-9$ & 0.0 & 0.0 & 0.0 \\
$10-19$ & 0.1 & 3.6 & 0.1 \\
$20-29$ & 0.1 & 9.7 & 5.5 \\
$30-39$ & 1.7 & 24.7 & 14.4 \\
$40-49$ & 3.0 & 30.7 & 15.0 \\
$50-59$ & 15.3 & 23.8 & 11.0 \\
$60-69$ & 26.4 & 21.9 & 10.4 \\
$70-101$ & 53.4 & 12.4 & 4.3 \\
\hline
\end{tabular}

Source: PSID sample members in interviewed family units in 1985.

Note: To be counted as having remarried, the individual must be currently married.

spouse to death because their death is likely to precede that of their spouse.

Remarriage is relatively common for those having experienced divorce (see the third column of figures in Table 2). In most of the adult age ranges, about one-half of the women who have experienced divorce currently have a new spouse. The exception is elderly women, among whom only about one-third of the divorcees remarry. Remarriage following divorce is even more common for men than women; in most of the adult age ranges, about two-thirds to four-fifths of divorced males have remarried. This situation results in complex family obligations, especially for remarried adults who may have two sets of children to support, one from a first marriage and another from the second marriage. This complex set of obligations raises issues about equity and assurance of economic security for children (Hill, 1992b).

For children born out of wedlock and unmarried mothers the "family" member generally considered the main breadwinner-the father of the children-is not even an official member of the family and, in all likelihood, does not reside with them. This, in combination with 
the patterns of divorce, remarriage, and mortality, suggests a need to recompose the model portrait of the American family to allow for past as well as current marital ties and for ties between young children and parents, primarily fathers, who live elsewhere and may be difficult to identify.

\section{Family versus Household}

Policies and researchers often assume that family and household are the same, but they can be very different. Family is generally conceptualized as the collection of individuals related by blood, marriage, or adoption, whereas a household is composed of individuals sharing the same dwelling. But not all individuals related by blood, marriage, or adoption coreside, and the absence of key relatives from the household can substantially complicate the design and implementation of policies. The fact that both kin structures and household structures are subject to change over time further complicates matters.

Relational ties, coresidency ties, or both may be relevant in defining what is meant by "family" (see, for example, Bould, 1993; Levin, 1993), and the public as well as policy makers and family researchers vary substantially in the extent to which they consider these two elements when defining family. Individual differences in defining family begin as early as childhood. Studies of children's concepts of family show that very young children rely on coresidency ties in defining family and that girls expand their criteria for family to include relational ties earlier than boys do (Borduin, Mann, Cone, \& Borduin, 1990). Research reveals sex differences in definition of family among adults as well. Women tend to have larger families than men because they take into account an additional layer of relations. Whereas men tend to include only persons close to them, women tend to include not only those close to them but persons close to those persons (Levin, 1993; Trost, 1993).

Relational ties could be missed by household measures. Focusing again on the nuclear family, Table 1 provides evidence about the extent to which major relational ties are unobserved when only the relatives in the household are identified (an approach taken in many surveys and public programs). This table illustrates the differences in family structure based on blood, marriage, and adoption ties (labeled "Family Structure") and those based on coresidency (labeled "Household Structure"). The "Family Structure" figures show the prevalence 
of those with nuclear family relational ties, and the "Household Structure" figures show the prevalence of those residing with nuclear family members. A comparison of the patterns for the two structures shows the extent to which household structure is an accurate representation of family structure as defined by relational ties.

For children under age 20, the data mostly allow us to view coresidency ties with incomplete knowledge about whether key relatives are still living and living elsewhere. ${ }^{8}$ For many children, a key nuclear family member-the father-lives apart from them. Only about three-quarters of the children in the age groups 0-9 and 10-19 were living with a father, ${ }^{9}$ whereas at least 9 in 10 were residing with a mother. ${ }^{10} \mathrm{~A}$ restriction of parental ties to biological ones would yield lower counts, as the earlier discussion about stepparents suggested.

For the adult ages, the focus is more on the procreative nuclear family, and the data are better suited to comparing the relational ties with the coresidency ties. Procreative nuclear families tend to be formed by adults in their twenties and thirties (as indicated by the sharp drop in the percentage with no children and no spouse in the fourth column of Table 1). From that point onward through most of their adult life they tend to have relational ties that bind them to a procreative nuclear family (note the high percentages with both children and a spouse in the third column of figures from ages 30-39 through 70-101). An exception is elderly women, who are likely to have lost a spouse to death but still have living children.

A comparison of the percentage with current spousal relational ties versus current spousal coresidency ties indicates that ties to a current spouse are, for the most, accurately reflected by household structure. At all adult ages only a small percentage of those with a current spouse are not residing with that spouse.

The overall pattern regarding presence of children is quite different. The thirties are the only age range during which the majority of adults coreside with their entire complement of procreative nuclear family members. From their thirties onward (for men from their twenties onward), there is considerable disbursement of children to other locations (compare the first and sixth columns of figures). In their forties only about $40 \%$ of adults coreside with all their children. And the percentage drops to well under $10 \%$ from age 60 onward. This is not to say that all children are absent from the household. Adults in their thirties, forties, and fifties tend to have at least one child present in the household. Hence throughout adulthood, even though a household will often contain at least one child, there is a 
TABLE 3

Percentage of Individuals Who Have Children Living Elsewhere, by Age of Child, 1985

\begin{tabular}{lcc}
\hline $\begin{array}{c}\text { Age and } \\
\text { sex }\end{array}$ & $\begin{array}{c}\text { Percentage who have: } \\
\text { Child of any age } \\
\text { living elsewhere }\end{array}$ & $\begin{array}{c}\text { Child under age 18 } \\
\text { living elsewhere }\end{array}$ \\
\hline $0-9$ & 0.0 & 0.0 \\
$10-19$ & 0.0 & 0.0 \\
$20-29$ & 8.3 & 7.8 \\
$30-39$ & 19.6 & 18.3 \\
$40-49$ & 46.7 & 20.4 \\
$50-59$ & 82.7 & 5.9 \\
$60-69$ & 87.8 & 2.6 \\
$70-101$ & 75.8 & 0.6 \\
Females & & \\
$0-9$ & 0.0 & 0.0 \\
$10-19$ & 0.0 & 0.0 \\
$20-29$ & 4.3 & 4.0 \\
$30-39$ & 11.5 & 8.0 \\
$40-49$ & 54.4 & 5.2 \\
$50-59$ & 86.7 & 2.3 \\
$60-69$ & 84.9 & 1.0 \\
$70-101$ & 74.1 & 0.3 \\
\hline
\end{tabular}

Source: PSID sample members in interviewed family units in $\mathbf{1 9 8 5 .}$

good chance, especially after middle age, that at least one child will be absent.

Table 3 provides information on the age of children living elsewhere. Sizable segments-about one in five-of adult men in their thirties and forties have young children living elsewhere and, hence, obligations that go beyond their own households. Three-quarters of the adults aged 70 and older have adult children who do not live with them; ${ }^{11}$ this is a potential resource of assistance that does not show up in a household listing of family members.

Hence many parent-child ties span different households, some involving young children and some involving adult children, and this complication should be taken into account in policy design. Noncustodial parents have become more common as divorce and out-of-wedlock birth rates have risen and the elderly have come to live independently of their adult children.

To the extent that relational ties and economic ties intertwine as they extend across households, the dispersion of parent-child ties across households can have important implications for the design of 
policies and research of economic issues such as the substitutability of private transfers for public support and effects of interhousehold transfer flows on the labor force participation and economic well-being of the donor or recipient. Parents may call upon adult children for assistance when health problems arise. Although a spouse is usually an elderly person's first line of defense in marshaling caregiving assistance, children are often next in line (see Soldo \& Hill, 1993, for a review of these findings). Mounting concern about health care costs for the elderly and proposals for encouraging greater family involvement make it important to know about the parent-child ties that span separate households as well as those within households.

Coresidence is not confined to nuclear family members. The sharing of a household with other people is not necessarily confined to nuclear family members. Individuals may choose to share their household with more distant relatives or nonrelatives, and a sizable segment of the population does so. As the fifth column of figures in Table 4 indicates, across the different age/sex subgroups from about 10 to $20 \%$ of the individuals are residing with someone other than a nuclear family member. Even children's households are highly divergent from a nuclear family structure (see Furukawa, 1994). Many children live in "blended families," that is, with a stepparent, stepsibling, and/or halfsibling present in the same household. As of summer 1991, about one in seven children resided in a blended family. In addition, life in an extended family is common among children. About one in eight children were living in an extended family-a family containing someone other than a stepparent who is not part of the child's nuclear family.

The type of coresident who is not a nuclear family member varies substantially across individuals, with some distinct patterns by age and sex. Young adults are more likely than older adults to share a household with a partner (a "cohabitor"). About 7\% of the adults in their twenties are living with but not married to a partner. Men, especially those in their thirties and forties, are more likely than other subgroups to have a stepchild in their household. About $8 \%$ of the men in their thirties and forties have at least one stepchild living with them. Grandchildren appear in the households of adults aged 40 or older, with 1 to $5 \%$ of the individuals in these age ranges sharing their household with at least one grandchild.

Living alone is not synonymous with having no nuclear family members. Having nuclear family members does not necessarily mean 


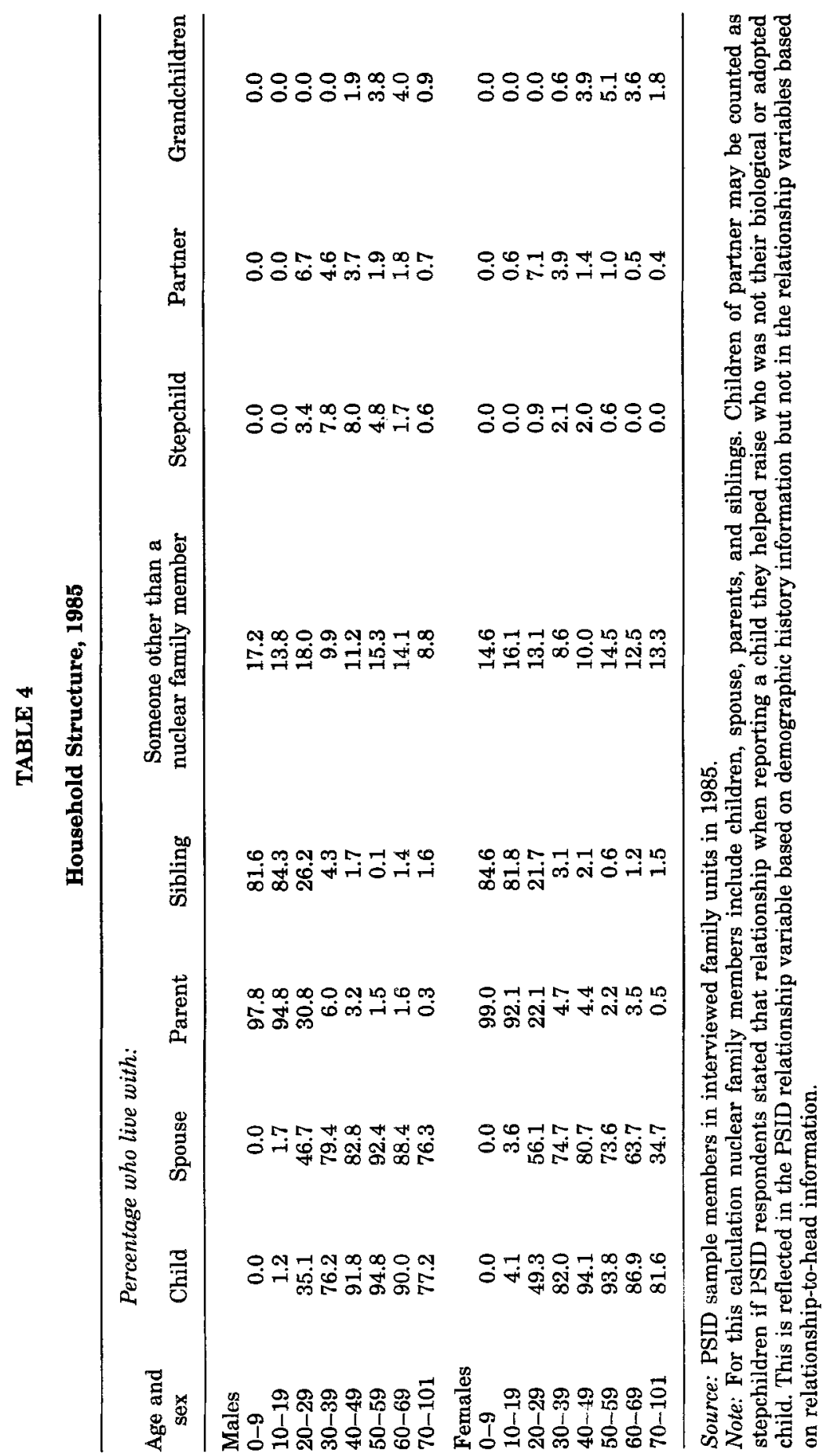


that an individual shares a dwelling with them. This was seen earlier in the overall comparisons of family structure and household structure, but it is a particularly relevant issue for individuals living alone because they are sometimes classified as being outside any family structure.

Here the central focus is on the extent to which single-person households have ties to children living elsewhere. ${ }^{12}$ This issue is most policy-relevant for the elderly because it is indicative of the potential for assistance from private sources. Table 5 shows that most middle-age and elderly individuals living alone do have ties to children living elsewhere. ${ }_{0}^{13}$ Elderly women, especially those aged 70 and over, are the most likely to be living alone,${ }^{14}$ and about 8 in 10 of them have at least one child living elsewhere. Hence this vulnerable subgroup has more in the way of family resources than is evident from their living arrangements.

Families and households are not stable over time. Although policies and researchers often implicitly assume an unchanging family struc-

TABLE 5

Family Structure of Single-Person Households, 1985

\begin{tabular}{lcrc}
\hline $\begin{array}{c}\text { Age and } \\
\text { sex }\end{array}$ & $\begin{array}{c}\text { Percentage living } \\
\text { as a single-person } \\
\text { household }\end{array}$ & $\begin{array}{c}\text { Sample } \\
\text { size }\end{array}$ & $\begin{array}{c}\text { Percentage of single-person } \\
\text { households with children } \\
\text { living elsewhere }\end{array}$ \\
\hline Males & & & \\
$0-9$ & 0.0 & 0 & - \\
$10-19$ & 0.5 & 7 & 13.2 \\
$20-29$ & 14.2 & 227 & 43.0 \\
$30-39$ & 13.0 & 171 & 79.5 \\
$40-49$ & 8.8 & 55 & 98.5 \\
$50-59$ & 4.7 & 36 & 88.9 \\
$60-69$ & 6.3 & 41 & 53.3 \\
$70-101$ & 16.5 & 48 & - \\
Females & & & - \\
$0-9$ & 0.0 & 0 & 4.9 \\
$10-19$ & 0.4 & 6 & 13.1 \\
$20-29$ & 8.3 & 114 & 53.6 \\
$30-39$ & 8.9 & 105 & 77.5 \\
$40-49$ & 4.6 & 34 & 81.4 \\
$50-59$ & 12.9 & 96 & 83.5 \\
$60-69$ & 22.6 & 259 & 54.7 \\
$70-101$ & 49.2 & 1,345 & \\
All & 10.5 & 259 & \\
\hline
\end{tabular}

Source: PSID sample members in interviewed family units in 1985. 
ture over time, families and households are highly subject to change. Concepts such as "family" and "household" are difficult to define in a dynamic context, and different approaches have been used to trace the changes that occur over time (see Citro \& Watts, 1986; Duncan \& Hill, 1985; Hill, 1992a; McMillen \& Herriot, 1985; Ruggles, 1990, for a discussion of the issues associated with identifying longitudinal households). One approach is to define families and households in a way that allows distinctions between units remaining intact versus discontinuing or forming. Another approach is to trace individuals as they move from one family or household to another and delineate the differences in their family or household circumstances. But whether the fluidity in families and households is measured from the perspective of the family/household unit or from the perspective of individuals who are members of the units, the evidence shows considerable change.

Assessing change from the perspective of longitudinal household units yields a finding that over a one-year period $9.0 \%$ of the households that had existed at the start of the year were no longer in the same category by the end of the year. Over a two-year period the percentage of initial households subsequently discontinuing rose to $15.6 \%$ (U.S. Bureau of the Census, 1992b, Table A).

Another way to look at the fluidity in living arrangements is to take a sample of individuals at a given point in time and trace backward through time the composition of the households in which they have resided. The PSID data allow us to do this as well as extend the time frame over which change could occur. Table 6, which shows the percentage of individuals having experienced no change in their household composition over a 10-year period, shows striking evidence that none of the age/sex subgroups has an unchanging household as their modal situation (see first column of figures in Table 6). ${ }^{15}$ The subgroups most likely to have been in stable households are elderly men and women. Even so, only 30 to $40 \%$ of them lived with the same people throughout the preceding 10 years. Adults in their twenties and thirties are especially likely to have experienced changes in household structure during the previous decade even if they are currently living with their entire nuclear family (see second column of figures).

More stability in household structure over the decade occurs among middle-age adults currently living with their entire nuclear family. For these people, stable household membership is the modal pattern. Even among them, however, the percentage whose household structure changed during the previous decade is substantial. 
TABLE 6

Stability of Living Arrangments over 10 Years, 1976-1985

\begin{tabular}{lcc}
\hline & \multicolumn{2}{c}{$\begin{array}{c}\text { Percentage who have lived with same people throughout } \\
\text { preceding 10 years: }\end{array}$} \\
$\begin{array}{lcc}\text { Age and } \\
\text { sex }\end{array}$ & All & $\begin{array}{c}\text { Those living with all children }+ \\
\text { spouse in 1985 }\end{array}$ \\
\hline Males & & \\
$0-9$ & 0.2 & - \\
$10-19$ & 23.2 & 0.0 \\
$20-29$ & 4.1 & 0.0 \\
$30-39$ & 2.8 & 4.3 \\
$40-49$ & 24.0 & 50.2 \\
$50-59$ & 10.5 & 71.3 \\
$60-69$ & 10.0 & 56.2 \\
$70-101$ & 42.4 & 0.0 \\
Females & & \\
$0-9$ & 0.3 & - \\
$10-19$ & 15.8 & 0.0 \\
$20-29$ & 3.3 & 0.4 \\
$30-39$ & 5.5 & 8.3 \\
$40-49$ & 22.0 & 57.5 \\
$50-59$ & 7.1 & 73.1 \\
$60-69$ & 10.9 & 84.2 \\
$70-101$ & 34.0 & 0.0 \\
\hline
\end{tabular}

Source: PSID sample members in interviewed family units in 1985.

Note: Most all of the individuals in this age range would not have been living throughout the preceding 10 years because they were born some time after the start of the decade.

The degree of fluidity in living arrangements may well be higher for certain racial or ethnic subgroups. Hunter and Ensminger (1992), for example, document a very high degree of diversity and fluidity in the living arrangement of African American children.

\section{Summary and Discussion}

\section{Diversity and Fluidity of Family and Household Structure}

The picture of the typical American family as a coresident nuclear unit is not well aligned with current patterns of relational ties and living arrangements. The coresident nuclear family is a poor characterization of the family situation of adults, except those in their thirties. It is the modal family situation of U.S. children; however, sizable 
segments of children are in other family situations, often with their father living elsewhere and quite possibly remarried.

The coresident nuclear model should be considered $a$ model rather than the model of family. Past as well as current marital ties need to be considered in defining "family," and divorce rather than death should be the expected cause of the loss of the main breadwinner in the family, except among elderly women. Parent-child ties involving either young children or adult children often span separate households. And coresidents can include individuals other than nuclear family members.

Rather than trying to shape concepts of the family from a single mold, policy makers and researchers would be better advised to recognize the high degree of diversity and fluidity in family and household structure (see Bould, 1993; Hernandez, 1993; Liss, 1987; Trost, 1993; for similar arguments; see Crispell, 1991; Germain, 1994; Riche, 1991; Smith, 1992; and Sorrentino, 1990, for discussions of the changes in families in recent decades). Relational ties vary over the life course as one's procreative family forms and one's family of birth disappears, and marriage, divorce, remarriage, fertility, and mortality reshape the size and composition of an adult's procreative family.

Changes in rates of marriage, divorce, remarriage, fertility, and mortality reshape families and households in the aggregate as well (see, for example, Hernadez, 1993), and dramatic shifts in these rates of demographic change in recent decades foretell quite different circumstances for family and household ties in the coming years. For some time, U.S. patterns of living arrangements have reflected trends toward more independent living and hence fewer coresidency ties, especially among the elderly. But the growing divorce and remarriage rates speak of changes in relational ties as well. The spouse, primarily, and children, secondarily, have been key relatives in the provision of help to adults in strained financial circumstances or poor health (see Soldo \& Hill, 1993, for a review of literature on this topic). The high incidence of divorce in recent decades, often with no remarriage in the wings, in conjunction with historically low fertility rates paint a future in which a large proportion of middle-age and elderly persons have little access to help from relatives. Many will have no spouse to assist with economic and health problems and few or no children to call upon in times of need. At the same time, with sizable rates of remarriage among those divorcing, many of the relational ties binding adults to the next generation will be ties of a more tenuous nature than biological or adoptive ones-ties remote enough to attach the 
prefix "step" to their label. This, in conjunction with the loose attachment in recent decades of many biological parents living apart from their young children, clouds the obligations of parents to children as well as of children to parents. The patterns of intergenerational transfers between parents and their adult children are likely to undergo substantial change, most likely decreasing in frequency unless changes in public programs erode the public support base sufficiently to force movement in the other direction.

Changes such as these mean greater diversity in family and household circumstances, making a uniform definition of family ill suited to the reality. A uniform definition of family also can be less than desirable in designing policy or studying the behavior of families. Although variety in the definition of family presents challenges for multiple program participation and interdependencies across family members (see, for example, Doyle \& Long, 1990), the definition should be adapted to fit the particular type of policy and research issue. To illustrate:

1. for economic decision making it is often appropriate for the "family" to be the collection of persons sharing the same dwelling, but

2. for issues relating to child development or availability of assistance for frail elderly it can be more useful for "family" to refer to a person's collection of parents and children regardless of their living arrangements, and

3. for private assistance flows all kin may be relevant, whether or not they coreside.

The fluidity, or changeability, of family is a dimension frequently neglected by policy makers and by researchers using cross-sectional data, but longitudinal data on coresidency ties indicate that the modal situation for adults and children is change. A prospective measure of household change indicates that about $15 \%$ of households discontinue within a two-year period. A decade-long retrospective measure of the incidence of individuals experiencing change indicates that most individuals, regardless of age, underwent a change in household composition and at the end of the decade were not residing with the same set of individuals they were residing with at the start of the decade.

For understanding and anticipating behavior, it may be important to know what the public considers to be a family, how self-defined concepts of family are formed, and how they shape behavior (Levin, 
1993). Public concepts of family may influence public acceptability and hence the effects of family-related policies. Indications are that self-definitions of family take account of relational ties, living arrangements, or both but that the public varies in the way these aspects shape their definitions of family.

\section{Effects of Policy on Family and Household Structure}

Policy makers and researchers also should keep in mind potential effects of policies on family and household structure and who benefits or is harmed. For example, policies that reward or penalize an adult for having additional children will, in all likelihood, affect children as well as adults. To illustrate, a newborn child can become an innocent victim of policies aimed at encouraging women to rely less on public assistance by withholding Aid to Families with Dependent Children funds for the added child. Policies that reward or penalize marriage, such as tax differentials based on marital status, can affect marriage behavior, and policies that define family on the basis of living arrangements (e.g., exclusionary provisions such as presence of a father disqualifying his children for public assistance) can influence who shares housing with whom. One of the ways that individuals can cope with economic hardship is to share housing with others. Policies that extract all of the economic benefits that can accrue to individuals from sharing housing reduce the available coping strategies. A desirable, but possibly unattainable, goal of most policies should be neutrality with respect to living arrangement and family structure. Assessments of deviation from neutrality, and who benefits or loses, should be a part of the comprehensive evaluation of program effects.

\section{Functions of Families and Households}

By focusing on the structure of families and households, this article shows that actual population patterns regarding structure deviate substantially from the assumptions of many policies. But structure is only part of the important considerations about family. Assumptions about the functions of families and households are also crucial, and the fit between assumed functions and actual functions merits attention. Currently available data allow analysis of functions served by the labor market participation of family members, but analysis of broader issues of time allocation (e.g., time spent fostering the devel- 
opment of children) and of resource allocation is hindered by the lack of sufficient data.

Policies make implicit assumptions about the pooling of resources, but little is known about this. Policies tend to assume that coresident nuclear family members pool all resources, that distantly related or unrelated individuals pool few resources even when they coreside, and that nuclear family members living in different locations fall somewhere in between. But little is known about the sharing and distribution of resources by family and household members. Although there are now considerable data on income flows into households, there is little information about how those financial resources are allocated across household members. It may be, for example, that money transfers intended for young children (e.g., child support payments) are not actually allocated to them (Weiss \& Willis, 1993). In addition, until recently there has been little information on flows of economic resources between households. Assumptions about pooling of resources and sharing of expenses are more precarious after children become adults. The scarcity of information about transfers between family members living apart has been reduced with the advent of questions about intergenerational transfers embedded in several national studies (e.g., the 1988 wave of the PSID, SIPP, the National Study of Families and Households [NSFH], the Health and Retirement Study [HRS], and the Asset and Health Dynamics [AHEAD] study). ${ }^{16}$ Little data are available, however, about the distribution of resources across family members coresiding.

Policies take account of some but not all aspects of time allocation. The model of economic behavior and time allocation for policies developed in the 1930 s was the combination of a husband/father participating in the labor force and a homekeeping wife/mother not participating in the labor force. Dual earners are now more typical among nuclear families. Beyond the simple dichotomy of in or out of the labor force and hours of paid work, however, little account is taken of time allocation by researchers or policy makers (for exceptions see Hernandez, 1993; Juster \& Stafford, 1991; Presser, 1989; Soldo \& Hill, in press; Stafford \& Sundstrom, 1994). Time is an important resource that is rarely measured even though its use by family members-to provide child care, elder care, housekeeping, home maintenance, transport to appointments or activities-can affect the well- 
being of all of its members. It is important to recognize that adults and children with family members living elsewhere are not likely to benefit as fully from the time resources of family members absent from their household as they would if those individuals were present in their household, but there may still be some transfer of services across households.

\section{Conclusion}

In sum, it is important in policy design and research of family-related issues to have information about a variety of aspects of family, including structural and functional dimensions. Ideally, data would be available to examine simultaneously the many facets of family and compare them to underlying assumptions about family. This would help guide policy design and further understanding of human behavior. Unfortunately, few data sets provide enough of the necessary elements. The PSID and Census Bureau data used here are among the rare sources of data combining comprehensive information about both relational and coresidency ties. Rarer still are sufficient data on the pooling of resources and time allocation. Without information about each and every one of these aspects of family, assumptions underlying policy design and research on family-related issues become a shot in the dark or fabrication based on old, and possibly outmoded, stereotypes.

\section{Notes}

1. A comparison of the ratio of the number of noninfant deaths to the number of divorces helps illustrate the greater role that mortality played in family life in the 1930s: noninfant deaths were 6.1 times as common as divorces in 1930; by 1988 they were only 1.8 times as common as divorces. (U.S. Bureau of the Census, 1984, Table No. 80; U.S. Bureau of the Census, 1990, Table 80.)

2. PSID data for $\mathbf{1 9 8 8}$ indicate that between one-half and two-thirds of adults aged 25 or older were engaged (as either donors, recipients, or both) in transfers of time or money between households. Interhousehold transfers in the form of support, gifts, or loans averaged (including those giving nothing) about $\$ 500$ per year, and transfers of time (services) averaged about 130 hours per year (Hill, Morgan, \& Herzog, 1993). SIPP data show that the average provider of support to someone outside the household in 1988 gave about $\$ 3,000$; approximately $5 \%$ of all adults 
provided what they considered support (U.S. Bureau of the Census, 1992a, Table A).

3. As of 1988, the majority (56\%) of recipients of financial support from outside the household were young (under age 18) children, an additional $10 \%$ were adult children, and less than $15 \%$ were parents of the donor (U.S. Bureau of the Census, 1992a, Table A).

4. One aspect of family head that differs in PSID from many other data sets begun since the early 1970 s is that, in husband-wife families, the head is automatically taken to be the husband. PSID began (in 1968) with this designation and, for consistency, has maintained it since.

5. Basic building blocks include relationships such as "biological child." Say that the relationship between person $A$ and person $B$ is unknown, but it is known that person $A$ is the "biological child" of a person C, who is the "biological child" of person B. The algorithm would generate the relationship "biological child of biological child"-in more common usage "grandchild"-for the relationship of A to B. On the file the relationship, if indirect via another person (e.g., mother of mother, or grandmother on mother's side), is indicated in full detail when enough information is available to do so.

6. Because the Relationship File omits individuals who have never appeared in an interviewed PSID family (e.g., children grown and living away from home at the start of the study), marital and fertility history information from the PSID's 1985 Ego-Alter File was also accessed and merged with the Relationship File data to link together comprehensive information about all marital and childbirth relationship ties.

7. The sample does not fully take account of immigration to the United States since 1968, when the study began, and cumulative attrition is sizable over the course of the panel even though annual attrition rates are small. Studies of the representativeness of the data, however, show close correspondence to population estimates from other major sources.

8. As is true of most data sets, the PSID does not always indicate if the missing father is still living and hence a genuine part of the children's relational ties. Parenting ties to a father are missed in the PSID if the father never lived with the child during the period 1968-1985, if the father was not in an interviewed family unit in 1985, or if the child was not reported in the father's fertility history as of 1985 .

9. The relatively low proportion of females aged 10-19 living with a father no doubt reflects the tendency for females to leave the parental nest at a somewhat younger age than males.

10. These figures track closely with comparable figures from SIPP showing in summer 1991 that $94.0 \%$ of the individuals under age 18 were residing with a mother and $75.5 \%$ were residing with a father. This divided into $72.8 \%$ living with both parents, $21.2 \%$ with a mother only, $2.7 \%$ with a father only, and $3.3 \%$ with no parent (Furukawa, 1994, Table 1).

11. At first thought, the three-quarters figure may seem low, but mortality among children largely accounts for this figure diverging from the approximately $85-90 \%$ for individuals aged $60-69$.

12. For the youngest age groups of adults it would also be desirable to know how many have parents living elsewhere. PSID data enhancements con- 
cerning ties to parents living elsewhere were first introduced in 1988. We do not use that information in this article because modest attrition between 1985 and 1988 complicates the representativeness of that data for our sample residing in family units interviewed in 1985.

13. The case counts for several of the age and sex subgroups are small enough to preclude definitive estimates. Such is the situation for all age subgroups of men aged 40 or older and for the 40-49 age category for women. The conclusion that sizable portions of single-person households, especially adults aged 40 or older, have children residing elsewhere is bolstered by findings from the Health and Retirement Study showing $62.5 \%$ of single men and $75.9 \%$ of single women aged 51-61 having children but not coresiding with a child (see component figures in Soldo \& Hill, in press).

14. The percentage of elderly living alone shown in Table 5 corresponds closely to CPS data, which indicate that in $199217.1 \%$ of males aged $70+$ and $46.1 \%$ of females aged $70+$ were living alone. These estimates are calculated from component figures in U.S. Bureau of the Census (1992b), Tables 8 and 26.

15. For methodological reasons, the estimates given here are probably an undercount of the extent of change in household structure. Individuals exiting from the study (because of death or attrition) may well have higher rates of change in household structure than their demographically similar counterparts not exiting from the study. The weights used in this analysis correct for attrition by assuming the rates of change for attriters are the same as those of demographically similar individuals remaining in the study. Higher rates of change for exiters, in conjunction with the omission of exiters in the current approach, would mean an undercount of change.

16. See Soldo and Hill (1993) for a review of research on intergenerational transfers in the economic, demographic, and sociological literature. U.S. Bureau of the Census $(1988,1992 a)$ discuss findings from SIPP on this topic.

\section{References}

Bachu, A. (1993). Fertility of American women: June 1992 (U.S. Bureau of the Census, Current Population Reports, Series P-20, No. 470). Washington, DC: U.S. Government Printing Office.

Bianchi, S. M. (1990). American's children: Mixed prospects. Population Bulletin, 45(1), 1-42.

Blum, B. B. (1994). Children and welfare reform. National Center for Children in Poverty, 4(1), 4-6.

Borduin, C. M., Mann, B. J., Cone, L., \& Borduin, B. J. (1990). Development of the concept of family in elementary school children. Journal of Genetic Psychology, $151,33-44$.

Bould, S. (1993). Familial caretaking: A middle-range definition of family in the context of social policy. Journal of Family Issues, 14, 133-151. 
Brandon, P. (1993-1994). The connection between family structure and entitlements affecting poor young children. Focus, 15(3), 27-34.

Burkhauser, R. \& Duncan, G. J. (1989). Economic risks of gender roles: Income loss and life events over the life course. Social Science Quarterly, 70, 5-23.

Citro, C., \& Watts, H. W. (1986). Patterns of household composition and family status change (Survey of Income and Program Participation, Working Paper No. 8609). Washington, DC: U.S. Bureau of the Census.

Cox, D. \& Raines, R. (1985). Interfamily transfers and income redistribution. In $M$. David \& T. Smeeding (Eds.), Horizontal equity, uncertainty, and measures of wellbeing (pp. 393-426). Chicago: University of Chicago Press.

Crispell, D. (1991). How to avoid big mistakes. American Demographics. 13(3), 48-50.

DaVanzo, J., \& Rahman, M. O. (1993). American families: Trends and policy issues. Santa Monica, CA: RAND.

Doyle, P., \& Long, S. K. (1990). The impact of the unit of analysis on measures of serial multiple program participation. In Individuals and families in transition: Understanding change through longitudinal data (pp.127-156). Washington DC: U.S. Government Printing Office.

Duncan, G. J., \& Hill, M. S. (1985). Conceptions of longitudinal households: Fertile or futile? Journal of Economic and Social Measurement, 13, 361-375.

Eggebeen, D. J. (1992). Family structure and intergenerational exchanges. Research on Aging, 14, 427-447.

Ellwood, D. T. (1993). The changing structure of American families: The bigger family planning issue. Journal of the American Planning Association, 59, 3-8.

Furukawa, S. (1994). The diverse living arrangements of children: Summer 1991 (U.S. Bureau of the Census, Current Population Reports, Series P-70, No. 38). Washington, DC: U.S. Government Printing Office.

Germain, C. B. (1994). Emerging conceptions of family development over the life course. Families in Society: The Journal of Contemporary Human Services, 75, $259-268$.

Glazer, N. (1988). The limits of social policy. Cambridge, MA: Harvard University Press.

Hernandez, D. J. (1993). American's children: Resources from family, government and the economy. New York: Russell Sage Foundation.

Hill, M. S. (1992a). The future of SIPP for analyzing interactions of family composition and income change. Journal of Economic and Social Measurement, 18, 67-89.

Hill, M. S. (1992b). The role of economic resources and remarriage in financial assistance for children of divorce. Journal of Family Issues, 13, 158-178.

Hill, M. S., Morgan, J. N., \& Herzog, R. (1993, April). Intergenerational aspects of interfamily help patterns. Paper presented at the Population Association of America meetings, Cincinnati, $\mathrm{OH}$.

Hill, M. S., Servais, M. A., \& Solenberger, P. (1992, June). Tangled webs of family relationships: Untangling them with survey data. Paper presented at the International Conference on Social Science Methodology, Trento, Italy.

Hunter, A. G., \& Ensminger, M. E. (1992). Diversity and fluidity in children's living arrangements: Family transitions in an urban Afro-American community. Journal of Marriage and the Family, 54, 418-426.

Juster, F. T., \& Stafford, F. P. (1991). The allocation of time: Empirical findings, behavioral models, and problems of measurement. Journal of Economic Literature, 29, 471-522.

Koo, H. P., \& Gogan, H. C. (1990). The process of change in families and households. In Individuals and families in transition: Understanding change through longitudinal data (pp. 203-230). Washington, DC: U.S. Government Printing Office.

Levin, I. (1993). Family as mapped realities. Journal of Family Issues, 14, 82-91. 
Levitan, S. A., Belous, R. S., \& Gallo, F. (1988). What's happening to the American family? Baltimore: Johns Hopkins University Press.

Levitan, S. A., \& Gallo, F. (1990). Work and family: The impact of legislation. Monthly Labor Review, 113(3), 34-40.

Liss, L. (1987). Families and the law. In M. B. Sussman and S. K. Steinmetz (Eds.), Handbook of marriage and the family. New York: Plenum.

MacDonald, M. (1990). Family background, the life cycle, and inter-household transfers (Working paper). Madison: University of Wisconsin, Center for Demography and Ecology.

McDaniel, C. (1984, September). Personal correspondence.

McMillen, D. B., \& Herriot, R. (1985). Toward a longitudinal definition of households. Journal of Economic and Social Measurement, 13(3\&4), 360-365.

Morgan, D. L., Schuster, T. L., \& Butler, E. W. (1991). Role reversals in the exchange of social support. Journal of Gerontology: Social Sciences, 46, S278-S287.

Morgan, J. N. (1983). The redistribution of income by families and institutions and emergency help patterns. In G. J. Duncan and J. N. Morgan (Eds.), Five thousand American families-Patterns of economic progress (pp. 1-59). Ann Arbor, Michigan: University of Michigan, Institute for Social Research.

Morgan, J. N. (1984). The rule of time in the measurement of transfers and well-being. In M. Moon (Ed.), Economic transfers in the United States (pp. 199-233). Chicago: University of Chicago Press.

Presser, H. B. (1989). Can we make time for children? The economy, work schedules, and child care. Demography, 26, 523-543.

Rawlings, S. (1993). Household and family characteristics: March 1992 (U.S. Bureau of the Census, Current Population Reports, Series P20-467). Washington, DC: U.S. Government Printing Office.

Ruggles, P. (1990). Longitudinal analysis of federal survey data. (Survey of Income and Program Participation Working Paper Series No. 9007). Washington, DC: U.S. Bureau of the Census.

Riche, M. F. (1991). The future of the family. American Demographics, 13(3), 44-46.

Schoeni, R. F. (1993). Private interhousehold transfers of money and time: New empirical evidence, (RAND Labor and Population Program Working Paper Series 93-26). Santa Monica, CA: RAND.

Smith, D. S. (1992). The meanings of family and household: Change and continuity in the mirror of the American census. Population and Development Review, 18, 421-456.

Soldo, B. J., \& Hill, M.S. (1993). Intergenerational transfers: Economic, demographic, and social perspectives. Annual Review of Gerontology and Geriatrics, 13, 187-216.

Soldo, B. J., \& Hill, M. S. (in press). Family structure and transfer measures in the HRS: Background and overview. Journal of Human Resources.

Sorrentino, C. (1990). The changing family in international perspective. Monthly Labor Review, 113(3), 41-58.

Spitze, G., \& Logan, J. R. (1992). Helping as a component of parent-adult child relations. Research on Aging, 14, 291-312.

Stafford, F. P., \& Sundstrom, M. (1994, September). Time out for childcare and career wages of men and women. Paper presented at the 6th Annual Conference of the European Association of Labour Economists, Warsaw, Poland.

Trost, J. (1993). Family from a dyadic perspective. Journal of Family Issues, 14, 92104.

U.S. Bureau of the Census. (1984). Statistical abstract of the United States: 1985. Washington, DC: U.S. Government Printing Office.

U.S. Bureau of the Census. (1988). Who's helping out?: Support networks among American families: 1988. (Current Population Reports, Series P-70, No.13). Washington, DC: U.S. Government Printing Office. 
U.S. Bureau of the Census. (1990). Statistical abstract of the United States: 1990. Washington, DC: U.S. Government Printing Office.

U.S. Bureau of the Census. (1992a). Who's helping out?: Support networks among American families (Current Population Reports, Series P-70, No. 28). Washington, DC: U.S. Government Printing Office.

U.S. Bureau of the Census. (1992b). Studies in household and family formation: When households continue, discontinue, and form (Current Population Reports, Series P-23, No. 179). Washington, DC: U.S. Government Printing Office.

Weiss, Y., \& Willis, R. J. (1993). Transfers among divorced couples: Evidence and interpretation. Journal of Labor Economics, 11, 629-679.

Wetzel, J. R. (1990). American families: 75 Years of change. Monthly Labor Review, 113(3), 4-13.

\section{Appendix: Theoretical Foundations for the PSID Relationship File}

The development of the PSID Relationship File loosely followed the methodology of the "ethnogenealogical approach" to the analysis of kinship systems used by some anthropologists. (As Hill, Servais, and Solenberger, 1992, indicate, the approach was taken with advice from Chad McDaniel [1984]; any problems in implementing it, however, are the responsibility of Hill, Servais, and Solenberger.) The genealogical method describes family relationships in terms of "primitive" codes and builds chains of codes to determine relationships among people when only some of these relationships are given.

Anthropologists studying kinship systems attempt to develop principles for combining the chained codes that allow them both to reproduce the conventional folk descriptions of the society they are studying and to analyze underlying social patterns and processes. The same was done with the PSID Relationship File, grouping the chained codes so that they were manageable but also so that they were intelligible to members of the U.S. society of which the PSID families and individuals are part and useful to analysts of that society. Since there was no assurance that the chosen grouping would suit every analyst, the "field notes" (the original "primitive" chains) were included in the Relationship File to allow analysts to group the chained codes as they pleased.

In brief, the procedure was as follows:

1. Describe immediate family relationships among individuals in terms of a relatively small number of "primitive" relationships based on the eight relationships of the traditional nuclear 
family: wife, husband, mother, father, daughter, son, sister, brother.

2. Describe other family relationships in terms of combinations or chains of these "primitive" relationships, for example, "sister of mother" to describe one variety of "aunt."

3. Reduce the large set of relationships derived in 1 and 2 to a smaller, more manageable, analytically meaningful set of relationships based on conventional American-English definitions of kinship.

The procedure was a computer-assisted iterative program with the following broad steps:

1. Build a table of "primitive" relationships among family members.

2. Identify missing relationships.

3. Find all third persons to whom both people in the missing relationship are related.

4. Determine the shortest chain of the known relationships.

5. Fill in the missing relationship.

6. Repeat steps 2 through 5 until no more unknown relationships can be filled in or the relationship chain is too long to be of analytical interest.

Step 4 required special attention. Often two people with an undetermined relationship are both related to more than one other person, which means we must choose the "shortest" chain. The iterative procedure used in calculating strings of relationships added one link at a time so that the "shortness" of the alternative chains was not the number of links but rather the combined "distance" of the links. A distance value was assigned to each "primitive" relationship, and the sum of the distances of the links was used to determine the shortest chain. 